Корсак Виктор Владиславович, $\partial-p$ c.- $x$. наук, проф. кафедры «Инженерные изыскания, природообустройство и водопользование», Саратовский государственный аграрный университет имени Н.И. Вавилова. Россия.
410012, г. Саратов, Театральная пл., 1.

Тел.: (8452) 23-27-83.

Ключевые слова: препараты на основе гуминовых кислот; лук репчатый; орошение; темно-каштановые почвы; Поволжье.

\title{
THE INFLUENCE OF HUMIC ACIDS ON THE PRODUCTIVITY AND QUALITY OF BULB ONION ON IRRIGATED CHESTNUT SOILS IN THE SARATOV TRANSVOLGA REGION
}

Pronko Viktor Vasilievich, Doctor of Agricultural Sciences, Professor, Head of the Department of Science and Development, Life Force LLC. Russia.

Pronko Nina Anatolievna, Doctor of Agricultural Sciences, Professor of the chair "Engineering Surveying, Environmental Engineering and Water Consumption", Saratov State Agrarian University named after N.I. Vavilov. Russia.

Shushkov Yuri Sergeevich, Post-graduate Student of the chair "Engineering Surveying, Environmental Engineering and Water Consumption", Saratov State Agrarian University named after N.I. Vavilov. Russia.

Korsak Viktor Vladislavovich, Doctor of Technical Sciences, Professor of the chair "Environmental Management and Water Use", Saratov State Agrarian University named after N.I. Vavilov. Russia.

Keywords: humic acids based products; bulb onion; irrigation; dark chestnut soils; The Volga region.
There were tested humic acids based products by Life Force Limited Liability Company on irrigated dark chestnut soils in the Saratov Transvolga region. The subjects of study were bulb onion «Khalcedon» and products containing meso- (calcium) and trace elements (boron, copper, zinc). It was find out that spraying with a solution of Reasil micro Hydro Mix increased the yield of onion by $4.01 \mathrm{t} / \mathrm{ha}$ (9\% higher than control). The use of a solution of sodium humate with microelements promoted an increase in yield by $5.62 \mathrm{t} / \mathrm{ha}$ (13\% higher than control). The maximum productivity of onion $(60.48 \mathrm{t} / \mathrm{ha}$ on average over three years) was obtained with double application of Reasil Forte Amino Copper on the background of $\mathrm{Hu}$ mate $\mathrm{K}-\mathrm{Na}$ with microelements. Humic acids based products at the same time increased the commercial yield. The studied humic acids based products positively influenced the quality of the crop: the content of sugars, the accumulation of vitamin $C$ and nutrients in the bulbs are increased. The removal of nutrients from the soil with the onions harvest affected by humic acids based products was increased.

\section{ИЗУЧЕНИЕ ФИТОТОКСИЧНОСТИ ГЕРБИЦИДОВ, ПРИМЕНЯЕМЫХ ДЛЯ БОРЬБЫ С ГОРЧАКОМ ПОЛЗУЧИМ}

\author{
СИЛАЕВ Алексей Иванович, Филиал Саратовская научно-исследовательская лаборатория \\ ФГБНУ ВИЗР
}

МАХАНЬКОВА Татьяна Андреевна, ФГБНУ ВИЗР

Поляков Сергей Сергеевич, Филиал Саратовская научно-исследовательская лаборатория ФГБНУ ВИЗР

В состав препаратов, используемых для боръбы с горчаком ползучим, входят пиклорам и клопиралид, которые наряду с высокой гербицидной активностью способны проявлять фитотоксичность в отношении двудольных растений и представителей семейства Роасеа. Кроме того, появляется все больше данных, свидетельствующих не только о видовой, но и о сортовой чувствительности колосовых хлебных злаков к этим препаратам. Представленные данные показывают, что гербициды Гориак и Горгон практически не оказывают отрицательного воздействия на рост и развитие сортов яровой пшеницы Фаворит и Саратовская 55 на первых этапах их онтогенеза. Энергия прорастания и всхожесть семян были равны или превышали значения контрольного варианта на 2,0-4,0\%. Развитие стебля и формирование первичной корневой системы у обоих сортов носило положительную динамику. Увеличение по сравнению с контролем варьировало от 1,1 до 12,1\% и от 4,1 до 16,6 \% соответственно. В отношении озимой пшеницы четкой закономерности в действии изучаемых гербицидов не выявлено. Зеленая масса растений всех сортов как яровой, так и озимой пшеницы равнялась или несколько превышала контроль.

Введение. Горчак ползучий, или розовый (Acroptilon repens), относится к группе корнеотпрысковых, крайне вредоносных и трудно искореняемых представителей сорной флоры.Первичным геноцентром происхождения этого растения являются горные районы Средней Азии, откуда, вероятнее всего, он и распространился по всему миру. Опираясь на глобальную базу данных Европейской организации по защите и карантину растений, с абсолютной уверенностью можно утверждать, что на сегодняшний день на нашей планете нет ни одного континента с достаточно развитым сельским хозяйством, где бы он не встречался. Ареал распространения сорняка охватывает многие страны Южной и Северной Америки, Западной и Восточной Европы, Бижнего Востока, Азии, Африки, Австралии, Океании [11].

Точных данных, отражающих его распространение по отдельным странам и континентам, в литературе практически нет. Однако, по данным EPPO Global Database, общая площадь земель сельскохозяйственного назначения в мире, засоренных Acroptilon repens, составляет 8-10 млн га. Достаточно сказать, что только в Республике Казахстан площадь пахотного фонда, на котором встречается 
горчак ползучий, по оценкам ряда экспертов, превышает 3,0 млн га, на Украине - около 1,0 млн га.

В России, по разным источникам, этот сорняк занимает от 420 тыс. до 1 млн га, чаще всего встречается в Калмыкии, Удмуртии, Ставропольском крае, Волгоградской, Оренбургской, Ростовской, Самарской и Саратовской областях $[2,4,7,8,10]$. В настоящее время для борьбы с горчаком используют разные по своему химическому составу препараты, многие из которых проявляют высокую фитотоксичность по отношению к культурным растениям. При этом на фоне постоянно возрастающих объемов их применения и расширения ассортимента риск проявления последействия только увеличивается. Это в равной мере справедливо как в отношении почвенных гербицидов, так и широко используемых по вегетирующим растениям $[2,3]$.

В последние годы с целью искоренения горчака ползучего все большее применение находят смесевые гербициды, отличающиеся высокой эффективностью и содержащие в своем составе в качестве действующего вещества пиклорам. Его характерной особенностью является высокая фитотоксичность в отношении не только двудольных культур. Он способен угнетать развитие многих видов растений, относящихся к семейству Pоасеа. С каждым годом появляется все больше данных, свидетельствующих не только о видовой, но и о сортовой чувствительности колосовых хлебных злаков к этому соединению $[6,9]$. В связи с этим вопрос изучения последействия подобных препаратов на последующие культуры севооборота, включая и зерновую группу, приобретает особую значимость.

Цель данной работы - изучение фитотоксического действия гербицидов, содержащих в своем составе пиклорам, на рост и развитие яровой и озимой пшеницы на первых этапах их онтогенеза.

Методика исследований. Исследования выполняли в соответствии с методическими указаниями [5].В опыт были включены препараты Горчак, ВГР, содержащий в своем составе 88,5 г/л дикамбы $+88,5$ г/л пиклорама $+177,0$ г/л клопиралида + 35,4 г/л ПАВ синтанола; Горгон, ВРК, в состав которого входит 350 г/л МЦПА кислоты + 150 г/л пиклорама нормой 1,25 и 2,5 л/га, а также Раундап, $\mathrm{BP}$, однокомпонентный препарат, содержащий 360 г/л глифосат кислоты, который применяли из расчета 8,0 л/га. Для их внесения использовали ранцевый опрыскиватель «Резистент-3590» с шириной захвата штанги 2 м, на которой были смонтированы щелевые, инжекторные, плоскофакельные ID-распылители. Норма расхода рабочей жидкости варьировала от 200 до 250 л/га.

Растения горчака ползучего опрыскивали в августе 2013 и в июле 2014 г., в безветренную погоду или при скорости ветра не более $3 \mathrm{~m} / \mathrm{c}$. Во всей серии полевых экспериментов площадь делянок составляла $25 \mathrm{~m}^{2}$, расположение их было рендомизированное, каждый вариант опыта включал в себя четыре повторности. На контрольных делянках гербициды не применяли [1]. Соответственно весной 2014 и 2015 г. с каждого варианта полевого опыта отбирали 10 кг почвы с глубины 0-20 см. В лаборатории этой почвой заполняли вегетационные сосуды объемом 2 л. После увлажнения на поверхность почвы раскладывали по 50 семян яровой пшеницы сорта Саратовская 55 и Фаворит, а также по 50 семян озимой пшеницы сорта Донская безостая и Жемчужина Поволжья. Сверху высеянные семена прикрывали слоем песка 1,5 см. Критерием оценки фитотоксичности служили энергия прорастания и всхожесть семян на 10-й день, а также длина корня, стебля и количество зеленой массы растений на 20-й день после всходов.

Результаты исследований. Исследования показали, что энергия прорастания семян в опытах с гербицидами Горчак и Горгон была высокой. Так, на 5-й день после посева по разным вариантам опыта проросло от 90 до 94 \% семян яровой пшеницы сорта Фаворит. В контрольных вегетационных сосудах и эталонном варианте - не более $92,0 \%$. На 7-й день учета энергия прорастания увеличилась и варьировала от 92,0 до 98,0 \%, в то время как на 10-й день этот показатель оставался практически на том же уровне, что и через 7 дней после посева. Что касается всхожести семян, то наиболее высокой она была в тех вариантах, где гербициды Горчак и Горгон применяли в минимальной дозе (1,25 л/га), соответственно 98,0 и 96,0 \%. Использование их в дозе 2,5 л/га существенного влияния на всхожесть семян не оказывало (табл. 1).

У сорта Саратовская 55 энергия прорастания семян также была высокой. В вариантах, где применяли гербициды Горчак и Горгон, ее значения варьировали на 5-й день от 90,0 до 94,0 \% и на 7-й - от 92,0 до 96,0 \%, в контроле - 92,0 и 94,0 \% соответственно. Что касается лабораторной всхожести семян, то у сорта Саратовская 55 во всех вариантах опыта

Таблица 1

Влияние гербицидов Горчак и Горгон на энергию прорастания и всхожесть семян (2014-2015 гг.)

\begin{tabular}{|c|c|c|c|c|c|}
\hline \multirow{2}{*}{$\begin{array}{c}\text { Вариант } \\
\text { опыта }\end{array}$} & \multirow{2}{*}{$\begin{array}{c}\text { Норма } \\
\text { расхода, } \\
\text { л/га }\end{array}$} & \multicolumn{3}{|c|}{$\begin{array}{c}\text { Энергия прорастания } \\
\text { семян, \% }\end{array}$} & \multirow{2}{*}{$\begin{array}{c}\text { Всхожесть, } \\
\%\end{array}$} \\
\hline & & $\begin{array}{r}\text { 5-й } \\
\text { день } \\
\end{array}$ & $\begin{array}{r}\text { 7-й } \\
\text { день }\end{array}$ & $\begin{array}{l}10-и ̆ \\
\text { день }\end{array}$ & \\
\hline \multicolumn{6}{|c|}{ Фаворит } \\
\hline \multirow{2}{*}{ Горчак } & 1,25 & 92,0 & 98,0 & 98,0 & 98,0 \\
\hline & 2,5 & 90,0 & 94,0 & 94,0 & 94,0 \\
\hline \multirow{2}{*}{ Горгон } & 1,25 & 92,0 & 96,0 & 96,0 & 96,0 \\
\hline & 2,5 & 90,0 & 94,0 & 96,0 & 96,0 \\
\hline Раундап, ВР(St.) & 8,0 & 90,0 & 92,0 & 92,0 & 92,0 \\
\hline Контроль & - & 92,0 & 94,0 & 94,0 & 94,0 \\
\hline \multicolumn{6}{|l|}{$\mathrm{HCP}_{0.95} 1,30$} \\
\hline \multicolumn{6}{|c|}{ Саратовская 55} \\
\hline \multirow{2}{*}{ Горчак } & 1,25 & 92,0 & 94,0 & 94,0 & 94,0 \\
\hline & 2,5 & 94,0 & 94,0 & 94,0 & 94,0 \\
\hline \multirow{2}{*}{ Горгон } & 1,25 & 90,0 & 92,0 & 92,0 & 92,0 \\
\hline & 2,5 & 94,0 & 96,0 & 96,0 & 96,0 \\
\hline Раундап, ВР(St.) & 8,0 & 90,0 & 92,0 & 92,0 & 92,0 \\
\hline Контроль & - & 92,0 & 94,0 & 96,0 & 96,0 \\
\hline \multicolumn{6}{|l|}{$\mathrm{HCP}_{0.95} 1,26$} \\
\hline
\end{tabular}


этот показатель был на 2,0-4,0 \% ниже контроля (табл. 1). Оценивая действие гербицидов, применяемых для подавления горчака ползучего, следует отметить их положительное влияние на рост и развитие проростков на первых этапах онтогенеза. Так, через 20 дней после появления всходов длина стебля яровой пшеницы сорта Фаворит достигала в контроле 27,1 см, тогда как в вариантах опыта с препаратом Горчак (1,25 и 2,5 л/га) этот показатель был выше на 12,1 и 10,7 \%. Аналогичная закономерность прослеживалась и в опытах с гербицидом Горгон, длина стебля была выше, чем в контроле, на 7,7 и 1,1 \% соответственно. Гербицид Раундап также превышал контроль на 11,8 \%. Длина первичной корневой системы у растений яровой пшеницы этого сорта на протяжении всего опыта превышала показатели контрольного варианта на 4,1-16,6 \%, а у эталонного препарата Раундап - на 4,1 \%. Что касается зеленой массы, то и в этом случае полученные данные по всем вариантам опыта или соответствовали значениям контроля, или же были несколько выше (табл. 2).

Использование противогорчаковых гербицидов также не оказывало негативного влияния на развитие яровой пшеницы сорта Саратовская 55. Через 20 дней после их применения длина стебля и первичной корневой системы по всем вариантам опыта, в том числе и у эталона, была выше контроля на $1,3-5,5 \%$ и на 5,0-14,0 \% соответственно. Масса надземной части растений этого сорта в контроле была несколько меньше или оставалась на уровне подобных значений в вариантах с гербицидами Горчак и Горгон (см. табл. 2).

Не установлено проявления фитотоксичности у применяемых в системе противогорчаковых мероприятий препаратов Горчак и Горгон и по отношению к сортам озимой пшеницы. Энергия прорастания семян в опытах с этими гербицидами оставалась высокой как у сорта Донская без-

Таблица 2

Влияние гербицидов Горчак и Горгон на длину стебля и корня, зеленую массу растений (2014-2015 гг.)

\begin{tabular}{|c|c|c|c|c|c|c|}
\hline \multirow{2}{*}{ Вариант опыта } & \multirow{2}{*}{$\begin{array}{c}\text { Норма } \\
\text { расхода, } \\
\text { л/га }\end{array}$} & \multicolumn{2}{|c|}{ Длина стебля } & \multicolumn{2}{|c|}{ Длина корня } & \multirow{2}{*}{$\begin{array}{l}\text { Кол-во } \\
\text { зеленой } \\
\text { массы, 1 }\end{array}$} \\
\hline & & CM & $\%$ & $\mathrm{~cm}$ & $\%$ & \\
\hline \multicolumn{7}{|c|}{ Фаворит } \\
\hline \multirow{2}{*}{ Горчак } & 1,25 & 30,4 & 112,1 & 11,2 & 116,6 & 16 \\
\hline & 2,5 & 30,0 & 110,7 & 10,8 & 112,5 & 15 \\
\hline \multirow{2}{*}{ Горгон } & 1,25 & 27,4 & 101,1 & 10,0 & 104,1 & 16 \\
\hline & 2,5 & 29,0 & 107,7 & 9,6 & 100 & 16 \\
\hline Раундап, ВР(St.) & 8,0 & 30,3 & 111,8 & 10,0 & 104,1 & 17 \\
\hline Контроль & - & 27,1 & 100 & 9,6 & 100 & 16 \\
\hline \multicolumn{7}{|l|}{$\mathrm{HCP}_{0.95} 1,24$} \\
\hline \multicolumn{7}{|c|}{ Саратовская 55} \\
\hline \multirow{2}{*}{ Горчак } & 1,25 & 31,8 & 104,6 & 10,9 & 109,0 & 16 \\
\hline & 2,5 & 31,5 & 103,6 & 10,7 & 107,0 & 16 \\
\hline \multirow{2}{*}{ Горгон } & 1,25 & 31,5 & 103,6 & 11,4 & 114,0 & 16 \\
\hline & 2,5 & 32,1 & 105,5 & 11,0 & 110,0 & 15 \\
\hline Раундап, ВР(St.) & 8,0 & 30,8 & 101,3 & 10,5 & 105,0 & 16 \\
\hline Контроль & - & 30,4 & 100 & 10,0 & 100 & 15 \\
\hline
\end{tabular}

остая, так и у сорта Жемчужина Поволжья.

Уже на 5-й день после посева по разным вариантам опыта проросло от 90 до $92 \%$ семян сорта Донская безостая. В контроле и эталонном варианте этот показатель также достигал $92 \%$. На 7-й и 10-й день эти значения практически не изменились. Всхожесть семян была наиболее высокой при применении гербицидов Горчак и Горгон в максимальной дозе (2,5 л/га) - 96,0 \%. В том случае, когда эти препараты использовали с нормой расхода 1,25 л/га, всхожесть семян оставалась на уровне контроля - 94,0 \% (табл. 3).

В экспериментах с сортом Жемчужина Поволжья энергия прорастания семян также была высокой и варьировала от 92,0 \% в контроле до 90,0-94,0 \% в опытных вариантах. Однако лабораторная всхожесть здесь практически по всем вариантам опыта оставалась на уровне контроля - 94,0-96,0 \% и лишь в варианте с эталонным препаратом Раундап она была на $2 \%$ ниже контрольного показателя (см. табл. 3).

Влияние противогорчаковых гербицидов на рост и развитие обоих сортов озимой пшеницы, в отличие от яровой, носило неоднозначный характер. У сорта Донская безостая длина стебля была меньше, чем в контроле, в случае, когда гербицид Горгон применяли с нормой расхода 1,25 л/га. Во всех остальных вариантах опыта этот показатель превышал значения контроля на $0,3-3,8$ \%. В то же время длина первичной корневой системы уступала показателям контроля на 1,0-6,7 \%. У сорта Жемчужина Поволжья установлена обратная закономерность. По всем вариантам опыта длина стебля была на 1,9-6,5 \% меньше, а длина зародышевых корней на 2,5-11,9 \% больше, чем в контроле. Применение гербицидов Горгон (1,25 л/га) и Раундап уменьшало и развитие корневой системы (табл. 4).

Заключение. Исследования показали, что использование для борьбы с горчаком ползучим

Таблица 3

Влияние гербицидов Горчак и Горгон на энергию прорастания и всхожесть растений (2014-2015 гг.)

\begin{tabular}{|c|c|c|c|c|c|}
\hline \multirow{2}{*}{ Вариант опыта } & \multirow{2}{*}{$\begin{array}{c}\text { Норма } \\
\text { расхода, } \\
\text { л/га }\end{array}$} & \multicolumn{3}{|c|}{$\begin{array}{c}\text { Энергия прорастания } \\
\text { семян, \% }\end{array}$} & \multirow{2}{*}{$\begin{array}{c}\text { Всхожесть, } \\
\%\end{array}$} \\
\hline & & $\begin{array}{c}\text { 5-й } \\
\text { день }\end{array}$ & $\begin{array}{c}\text { 7-й } \\
\text { день }\end{array}$ & $\begin{array}{l}10 \text {-й } \\
\text { день }\end{array}$ & \\
\hline \multicolumn{6}{|c|}{ Донская безостая } \\
\hline \multirow{2}{*}{ Горчак } & 1,25 & 90,0 & 92,0 & 94,0 & 94,0 \\
\hline & 2,5 & 92,0 & 94,0 & 96,0 & 96,0 \\
\hline \multirow{2}{*}{ Горгон } & 1,25 & 92,0 & 94,0 & 94,0 & 94,0 \\
\hline & 2,5 & 92,0 & 94,0 & 96,0 & 96,0 \\
\hline Раундап, ВР(St.) & 8,0 & 92,0 & 94,0 & 94,0 & 94,0 \\
\hline Контроль & - & 92,0 & 94,0 & 94,0 & 94,0 \\
\hline \multicolumn{6}{|l|}{$\mathrm{HCP}_{0.95} 1,14$} \\
\hline \multicolumn{6}{|c|}{ Жемчужина Поволжья } \\
\hline \multirow{2}{*}{ Горчак } & 1,25 & 92,0 & 94,0 & 94,0 & 94,0 \\
\hline & 2,5 & 94,0 & 94,0 & 94,0 & 94,0 \\
\hline \multirow{2}{*}{ Горгон } & 1,25 & 90,0 & 92,0 & 94,0 & 94,0 \\
\hline & 2,5 & 94,0 & 96,0 & 96,0 & 96,0 \\
\hline Раундап, ВР(St.) & 8,0 & 90,0 & 92,0 & 92,0 & 92,0 \\
\hline Контроль & - & 92,0 & 94,0 & 94,0 & 94,0 \\
\hline \multicolumn{6}{|l|}{$\mathrm{HCP}_{0.95} 1,09$} \\
\hline
\end{tabular}


Влияние гербицидов Горчак и Горгон на длину стебля, корня, зеленую массу растений (2014-2015 гг.)

\begin{tabular}{|c|c|c|c|c|c|c|}
\hline \multirow{2}{*}{ Вариант опыта } & \multirow{2}{*}{\begin{tabular}{|c|} 
Норма \\
расхода, \\
л/га
\end{tabular}} & \multicolumn{2}{|c|}{ Длина стебля } & \multicolumn{2}{|c|}{ Длина корня } & \multirow{2}{*}{$\begin{array}{c}\text { Кол-во } \\
\text { зеленой } \\
\text { массы, I }\end{array}$} \\
\hline & & $\mathrm{cM}$ & $\%$ & сM & $\%$ & \\
\hline \multicolumn{7}{|c|}{ Донская безостая } \\
\hline \multirow{2}{*}{ Горчак } & 1,25 & 32,1 & 102,5 & 10,5 & 99,0 & 13 \\
\hline & 2,5 & 31,4 & 100,3 & 10,1 & 95,2 & 14 \\
\hline \multirow{2}{*}{ Горгон } & 1,25 & 30,9 & 98,7 & 9,9 & 93,3 & 14 \\
\hline & 2,5 & 31,7 & 101,2 & 10,3 & 97,1 & 14 \\
\hline Раундап, BP(St.) & 8,0 & 32,5 & 103,8 & 10,3 & 97,1 & 15 \\
\hline Контроль & - & 31,3 & 100 & 10,6 & 100 & 14 \\
\hline \multicolumn{7}{|l|}{$\mathrm{HCP}_{0.25} 1,17$} \\
\hline \multicolumn{7}{|c|}{ Жемчужина Поволжья } \\
\hline \multirow{2}{*}{ Горчак } & 1,25 & 31,8 & 98,1 & 12,0 & 102,5 & 13 \\
\hline & 2,5 & 31,1 & 95,9 & 13,1 & 111,9 & 13 \\
\hline \multirow{2}{*}{ Горгон } & 1,25 & 31,2 & 96,2 & 10,0 & 85,4 & 13 \\
\hline & 2,5 & 31,2 & 96,2 & 12,4 & 105,9 & 14 \\
\hline Раундап, BP(St.) & 8,0 & 30,3 & 93,5 & 10,0 & 85,4 & 12 \\
\hline Контроль & - & 32,4 & 100 & 11,7 & 100 & 13 \\
\hline \multicolumn{7}{|l|}{$\mathrm{HCP}_{0.95} 1,13$} \\
\hline
\end{tabular}

гербицидов Горчак и Горгон практически не оказывало отрицательного воздействия на рост и развитие обоих сортов яровой пшеницы Фаворит и Саратовская 55 на первых этапах их онтогенеза. Энергия прорастания и всхожесть семян были равны или превышали значения контрольного варианта на 2,0-4,0 \% Развитие стебля и формирование первичной корневой системы у обоих сортов носило положительную динамику.

В отношении озимой пшеницы четкой закономерности в действии изучаемых гербицидов не выявлено. У сорта Донская безостая они незначительно стимулировали рост стебля (0,3-3,8 \%), но в определенной мере угнетали развитие зародышевых корней (1,0-6,7 \%). У сорта Жемчужина Поволжья, наоборот, развитие надземной части растений по сравнению с контролем шло менее интенсивно (1,9-6,5 \%), тогда как формирование первичной корневой системы опережало ее развитие в контроле $(2,5-11,9 \%)$.

Такой показатель, как зеленая масса растений всех сортов яровой и озимой пшеницы был одинаковым или несколько превышал значения контроля.
1. Доспехов Б.А. Методика полевого опыта. - 5-е изд. - М.: Агропромиздат, 1985. - 351 с.

2. Казакевич Л.И., Галкина З.П. Карантинные сорные растения и способы их уничтожения. - Волгоград, 1985. - С. 6-13.

3. Лебедев В.Б., Стрижков Н.И. Последействие гербицидов в севообороте // Агро XXI. - 2007. - №4-6. С. $23-25$.

4. Мальщев А.И. Распространение в России важнейших видов полевых сорных растений. - М., 1999. - 212 с.

5. Методические указания по регистрационным испытаниям фунгицидов в сельском хозяйстве. СПб., 2013. -280 с.

6. Петунова А.А., Маханькова Т.А. Сортовая устойчивость растений к гербицидам. - СПб., 2009. - 364 с.

7. Применение гербицида сангор (рекомендации) / Ю.Я. Спиридонов [и др.]. - М.: Агропромиздат, 1988. - C. 4-11.

8. Силаев А.И., Маханькова Т.А., Поляков С.С. Действие противогорчаковых гербицидов на критерии качества зерна яровой и озимой пшеницы // Аграрный научный журнал. - 2017. - № 12. - С. 52-54.

9. Сортовая устойчивость зерновых культур к новым гербицидам / В.И. Долженко [и др.] // Агро XXI. 2008. - №4-6. - С. 23-25.

10. Спиридонов Ю.Я., Спиридонова И.Ю. Горчак против горчака ползучего // Аграрный сектор. - 2015. №4(26). - C. 56-62.

11. Acroptilon repens: информация о распространении. EPPO Global Datbase, 2018// gd.eppo.int>taxon/CENRE.

Силаев Алексей Иванович, $\partial-p$ c.- $x$. наук, старший научный сотрудник, Филиал Саратовская научноисследовательская лаборатория ФГБНУ ВИЗР. Россия.

413123, г. Энгельс Саратовской обл., ул. Совхозная, 4.

Тел.: (8453) 75-44-12; e-mail: salexsey@prtcom.ru.

Маханькова Татьяна Андреевна, канд. с.-х. наук, ведущий научный сотрудник, ФГБНУ ВИЗР. Россия.

196608, г. Санкт-Петербург-Пушкин, шоссе Подбельского, 3.

Тел.: (8812) 476-43-84.

Поляков Сергей Сергеевич, ведущий агроном, Филиал Саратовская научно-исследовательская лаборатория ФГБНУ ВИЗР. Россия.

413123, г. Энгельс Саратовской обл., ул. Совхозная, 4.

Тел.: (8453) 75-44-12; e-mail: salexsey@prtcom.ru.

Ключевые слова: гербициды Горчак, Горгон; горчак ползучий; фитотоксичность; последействие; энергия прорастания; всхожесть; длина стебля; первичная корневая система.

\section{A STUDY OF THE PHYTOTOXICITY OF HERBICIDES USED TO CONTROL MOUNTAIN BLUET}

Silaev Alexey Ivanovich, Doctor of Agricultural Sciences, Senior Researcher, Saratov Research Laboratory (Branch), AllRussian Research Institute of Plant Protection. Russia.

Makhankova Tatyana Andreevna, Candidate of Agricultural Sciences, Leading Researcher, All-Russian Research Institute of Plant Protection. Russia.

Polyakov Sergey Sergeevich, Leading Agronomist, Saratov Research Laboratory (Branch), All-Russian Research Institute of Plant Protection. Russiaro

Keywords: herbicides; Gorchak, Gorgon; mountain bluet; phytotoxicity; aftereffect; germination energy; germination; length of stem; primary root system.

The composition of preparations used to control mountain bluet includes picloram and clopyralid, which, along with high herbicidal activity, are able to exhibit phytotoxicity against dicotyledonous plants and representatives of the Poacea family. In addition, there is more and more data showing not only the species, but also the varietal sensitivity of cereals to these preparations. The data presented show that Gorchak and Gorgon herbicides practically do not have a negative impact on the growth and development of spring wheat varieties Favorit and Saratovskaya 55 in the early stages of their ontogenesis. The germination energy and seed germination were equal or exceeded the control variant by 2.0-4.0\%. The development of the stem and the formation of the primary root system in both varieties have a positive trend. The increase ranged from 1.1 to $12.1 \%$ and from 4.1 to $16.6 \%$ in comparison with the control. Concerning winter wheat, there is no clear pattern in the action of the studied herbicides. The green mass of plants of all varieties of spring wheat and winter wheat equaled or slightly exceeded control. 